\title{
Efeito do Uso de Probiótico sobre o Desempenho e Atividade de Enzimas Digestivas de Frangos de Corte ${ }^{1}$
}

\author{
Andréa Cristina Frizzas de Lima², João Martins Pizauro Júnior ${ }^{3}$, Marcos Macari ${ }^{4}$, Euclides \\ Braga Malheiros ${ }^{5}$
}

\begin{abstract}
RESUMO - O presente estudo foi realizado com o objetivo de pesquisar o desempenho e quantificar a atividade das enzimas digestivas: amilase, lipase e tripsina, dos frangos de corte submetidos a diferentes níveis de energia, na dieta, e a diferentes doses de probiótico na ração. Foram utilizados 360 pintos da linhagem Hubbard, alimentados com dietas contendo 2.900 e $3.200 \mathrm{kcal}$ EM/kg, associadas com a adição de 0,200 e 400 ppm de probiótico (Bacillus subtilis - $10^{10}$ células viáveis esporuladas/grama de produto). Aos 14, 28 e 42 dias de idade, duas aves de cada unidade experimental foram abatidas, o pâncreas e o intestino delgado retirados, pesados e rapidamente congelados em nitrogênio líquido para posterior determinação das atividades enzimáticas. O delineamento experimental utilizado foi em parcelas subdivididas em seis tratamentos principais (dois níveis de energia vs três níveis de probiótico) e três tratamentos secundários (idades), com as parcelas distribuídas em três blocos ao acaso. Não foram encontrados efeitos significativos para a adição de probiótico na dieta em relação ao desempenho e às atividades enzimáticas. O nível de energia na dieta mostrou efeito significativo para o desempenho e as atividades da lipase e amilase (expressas por kg de peso vivo). Foi observado também que, em função da idade, houve diminuição da atividade da lipase, com exceção da amilase e tripsina pancreática, quando expressa em unidades por gramas de pâncreas. Os resultados obtidos neste experimento mostraram que a adição de probiótico (Bacillus subtilis) na dieta de frangos de corte não compromete o desempenho e nem a atividade das enzimas digestivas.
\end{abstract}

Palavras-chave: enzimas digestivas, frangos de corte, probiótico

\section{Effect of Probiotic Supplementation on Performance and Digestive Enzymes Activity of Broiler Chickens}

\begin{abstract}
The present study was carried out aiming to investigate the performance, as well to quantify the digestive enzymes activities for the following enzymes: amylase, lipase and trypsin from broiler chickens fed with diets containing different in energy levels and mixed with different probiotic doses. Three hundred and sixty one-day old broilers from the Hubbard-Peterson chick strain were used in this experiment. The birds were fed diets containing 2,900 and 3,200 kcal ME/kg to which were added 0, 200 and $400 \mathrm{ppm}$ of probiotic (Bacillus subtilis - $10^{10}$ sporulated viable cells/gram of product). At 14, 28 and 42 days of age, two birds of each treatment were sacrificed, the pancreas and small intestine withdrawn, weighed and frozen in liquid nitrogen for further enzymatic activity determinations. The experimental design was made up of subdivided parcels with 6 main treatments (two energy levels and three probiotic doses) and 3 secondary treatments (ages) with parcels distributed in 3 randomized blocks. It was not found statistically significant effects when probiotic was added to the diets with respect to performance and enzymatic activities. Energy levels had a significant effect on the performance and lipase and amylase activities (in $\mathrm{kg} /$ body weight). It was observed too, that as a function of age there has been a decrease of the lipase activity, with exception of pancreatic amylase and trypsin in $\mathrm{g} /$ pancreas. The results obtained in this experiment showed that the addition of probiotic (Bacillus subtilis) in the broiler's diet has not compromised their performance and neither digestive enzymes activities.
\end{abstract}

Key Words: broiler chickens, digestive enzymes, probiotics

\footnotetext{
${ }^{1}$ Pesquisa financiada pela FAPESP. Parte da Dissertação de Mestrado em Zootecnia da primeira autora, apresentada à FCAV, UNESPJaboticabal-SP. Bolsista do CNPq.

2 Zootecnista, doutora pela FCAV-UNESP-Jaboticabal.E.mail: afrizzasdelima@bol.com.br

3 Depto. de Tecnologia da FCAV-UNESP-Jaboticabal. E.mail: jpizauro@fcav.unesp.br. Via de Acesso Prof. Paulo Donato Castellane s/n CEP: $14884-900$ - Jaboticabal - SP.

${ }^{4}$ Depto. de Morfologia e Fisiologia Animal da FCAV-UNESP-Jaboticabal. E.mail: macari@fcav.unesp.br. Bolsista do CNPq.

${ }^{5}$ Depto. de Ciências Exatas da FCAV-UNESP-Jaboticabal. E.mail: euclides@fcav.unesp.br
} 


\section{Introdução}

O crescimento animal é um processo ordenado no qual ocorre o desenvolvimento dos órgãos que se tornam funcionais. Efeitos de seleção sobre o peso corporal num animal, enquanto jovem, são evidentes sobre o crescimento embrionário, resultando em diferenças entre as linhagens com relação ao tamanho relativo dos órgãos ao nascimento e durante seu crescimento. Vários estudos têm demonstrado que as funções digestivas das aves sofrem um processo de maturação com o decorrer da idade, tanto no que diz respeito à produção enzimática quanto ao processo de absorção de nutrientes. A influência da idade da ave, nesse processo, está relacionada à maturação dos órgãos que compõem o sistema digestório, incluindo a produção de enzimas digestivas como a lipase, amilase e proteases. Nos últimos anos, o emprego de enzimas de cereais e/ou de microorganismos intestinais têm alcançado grande sucesso na nutrição das aves. Tem sido proposto que a hidrólise aumenta a solubilidade em água dos carboidratos dos alimentos e o desempenho dos animais (Nir \& Nitsan, 1979).

Juntamente com o papel das enzimas digestivas, um outro aspecto que tem despertado o interesse de vários pesquisadores é o uso de probiótico na alimentação de frangos de corte. Esses organismos são introduzidos como aditivos na ração e contribuem para um melhor estabelecimento e manutenção de populações microbianas no trato digestório dos animais que vão competir com microorganismos indesejáveis, especialmente os patogênicos, por espaço e nutrientes. Quando são usados na alimentação de aves, os probióticos aumentam a eficiência alimentar, proporcionam melhor qualidade ao alimento, atuam como promotor natural de crescimento, diminuem as perdas devido a doenças infecciosas e reduzem os sintomas de estresse (Kozasa, 1989).

Os objetivos do presente estudo foram os de verificar o desempenho e também quantificar as atividades das enzimas digestivas: amilase, lipase e tripsina pancreática e intestinal, de frangos de corte submetidos a diferentes níveis de energia e a diferentes doses de probiótico na ração.

\section{Material e Métodos}

O experimento foi conduzido no Setor de Avicultura e no Laboratório de Enzimologia da Faculdade de Ciências Agrárias e Veterinárias da Universidade
Estadual Paulista “Júlio de Mesquita Filho", Campus de Jaboticabal. Foram utilizados 360 pintos da linhagem Hubbard, alojados em box com 20 aves/parcela. A ração fornecida foi à base de milho e farelo de soja, com dois níveis energéticos: 3.200 e $2.900 \mathrm{kcal}$ de $\mathrm{EM} / \mathrm{kg}$ e três níveis de probiótico (Calsporimâ BS FATEC, contendo $10^{10}$ células viáveis esporuladas de Bacillus subtilis por grama de produto), sendo adicionados: 0,200 e $400 \mathrm{ppm}$ nas fases inicial ( 0 a 28 dias) e final ( 29 a 42 dias). O balanceamento das rações utilizadas no período de 1 a 28 dias e de 29 a 42 dias de idade foi feito de acordo com o NRC (1994), e suas composições são mostradas na Tabela 1. A ração foi fornecida ad libtum.

Aos 14, 28 e 42 dias, duas aves de cada unidade experimental, tomadas ao acaso, foram pesadas e sacrificadas. Antes de serem abatidas para a retirada de órgãos, as aves passaram por um período de jejum alimentar de 3 a 4 horas, sem restrição do fornecimento de água. O pâncreas, o duodeno e o jejuno/íleo foram removidos, pesados e congelados, rapidamente, em nitrogênio líquido a, a seguir, foram armazenados a $-80^{\circ} \mathrm{C}$. Durante o período experimental, foram avaliados o peso médio, consumo de ração, conversão alimentar e índice de eficiência produtiva das aves.

Para a avaliação do desempenho das aves foi utilizado o delineamento em blocos casualizados, num esquema fatorial $2 \times 3$ ( 2 níveis de energia e três níveis de probiótico), com as parcelas distribuídas em três blocos. Para determinação das atividades enzimáticas, utilizou-se o esquema em parcelas subdivididas em seis tratamentos principais (combinação de dois níveis de energia e três níveis de probiótico) e três tratamentos secundários (idades de amostragem) com as parcelas distribuídas em blocos ao acaso.

As enzimas e proenzimas, estudadas no presente trabalho, foram obtidas de acordo com a metodologia descrita por Lima (1996). O pâncreas foi descongelado e homogeneizado (Omni-GLH) com tampão Tris-HCl $50 \mathrm{mM}, \mathrm{pH} 8,0$, contendo $\mathrm{CaCl}_{2} 50 \mathrm{mM}$, na proporção de 1:20 (peso:volume). O extrato bruto foi centrifugado a $14.000 \mathrm{~g}$ por 30 minutos sob refrigeração a $4^{\circ} \mathrm{C}$, filtrado em lã de vidro, aliquotado, armazenado a $-20^{\circ} \mathrm{C}$ e utilizado posteriormente para a determinação da atividade enzimática da atividade da amilase, da tripsina e da lipase. Já o extrato de jejuno/íleo foi obtido utilizando-se uma proporção de 1:5. Todas as operações foram realizadas a $4^{\circ} \mathrm{C}$.

A atividade da lipase foi determinada por titulometria, segundo o método de Sarda \& Desnuele

R. Bras. Zootec., v.32, n.1, p.200-207, 2003 
Tabela 1 - Composição percentual das rações experimentais

Table 1 - Composition of experimental diets percentual

\begin{tabular}{|c|c|c|c|c|}
\hline \multirow[t]{2}{*}{$\begin{array}{l}\text { Ingredientes } \\
\text { Ingredients }\end{array}$} & \multicolumn{2}{|c|}{$\begin{array}{l}1 \text { a } 28 \text { dias } \\
1-28 \text { days }\end{array}$} & \multicolumn{2}{|c|}{$\begin{array}{c}29 \text { a } 42 \text { dias } \\
29-42 \text { days }\end{array}$} \\
\hline & $2900 \mathrm{kcal} / \mathrm{kg}$ & $3200 \mathrm{kcal} / \mathrm{kg}$ & $2900 \mathrm{kcal} / \mathrm{kg}$ & $3200 \mathrm{kcal} / \mathrm{kg}$ \\
\hline Milho & 56,13 & 48,89 & 63,06 & 55,79 \\
\hline $\begin{array}{l}\text { Corn } \\
\text { Farelo de soja } \\
\text { Soybean meal }\end{array}$ & 37,41 & 38,81 & 31,69 & 33,09 \\
\hline Óleo de soja & 1,46 & 7,32 & 0,25 & 6,12 \\
\hline $\begin{array}{l}\text { Soybean oil } \\
\text { Suplemento* }\end{array}$ & 5,00 & 5,00 & 5,00 & 5,00 \\
\hline Suplement* & & & & \\
\hline Total & 100,00 & 100,00 & 100,00 & 100,00 \\
\hline $\begin{array}{l}\text { Proteína bruta } \\
\text { Crude protein }\end{array}$ & 21,90 & 21,90 & 20,00 & 20,00 \\
\hline $\begin{array}{l}\text { Metionina }+ \text { cistina } \\
\text { Methionine }+ \text { cystine }\end{array}$ & 0,78 & 0,77 & 0,73 & 0,73 \\
\hline $\begin{array}{l}\text { Sal } \\
\text { Salt }\end{array}$ & 0,36 & 0,36 & 0,36 & 0,36 \\
\hline $\begin{array}{l}\text { Cálcio } \\
\text { Calcium }\end{array}$ & 0,93 & 0,93 & 0,89 & 0,89 \\
\hline $\begin{array}{l}\text { Fósforo } \\
\text { Phosphorus }\end{array}$ & 0,47 & 0,47 & 0,44 & 0,44 \\
\hline
\end{tabular}

* Suplemento vitamínico mineral (Mineral and vitamin suplement), níveis (levels)/kg: Vit. A, 176.000 UI; Vit. D 3 , 40.000 UI; Vit. E, 500 mg; Vit. $\mathrm{K}_{3}, 100$ mg; Vit. B, 36 mg; Vit. B, 200 mg; Vit. B, 50 mg; Vit. B 12,560 mcg; Niacina (Niacin), 700 mg; Biotina (Biotin), 3 mg, Ác. pantotênico (Panthotenic acid), 500 mg; Ác. fólico (Folic acid), 30 mg; Colina (Choline), 20 g; Fe, 1.100mg; Cu, 300 mg; Mn; 1.800 mg; Zn, 1.200 mg; I, $24 \mathrm{mg}$; Selenito de sódio (Sodium selenite), $3 \mathrm{mg}$; Metionina DL (Metionine DL), $20 \mathrm{~g}$; Fosfato bicálcico (Dicalcium phosphate), $380 \mathrm{~g}$ (304 g na fase final/304 $\mathrm{g}$ in finishing phase); Carbonato de cálcio (Calcium carbonate), $176 \mathrm{~g}$ (141 g na fase final/141 g in finishing phase); Nitrovin, $2 \mathrm{~g}$; Coccidicida (Coccidicide), $10 \mathrm{~g}$; Antioxidante (Antioxidant) (BHT) $1 \mathrm{~g}$.

(1958). Foi utilizado emulsão de óleo de oliva (SIGMA 800.1) como substrato, em presença de taurodeoxicolato de sódio $6 \mathrm{mM}, \mathrm{NaCl} 0,15 \mathrm{M}$, $\mathrm{CaCl}_{2} 1 \mathrm{mM}$, tampão Tris(hidroximetil)aminometano $0,2 \mathrm{~mol} / \mathrm{L}, \mathrm{pH} 8,0$ e excesso de colipase de frango parcialmente purificada (Brockman, 1981).

Para a extração da enteroquinase, a mucosa duodenal foi colhida com o auxílio de uma espátula de metal, homogeneizada em tampão Tris- $\mathrm{HCl} 50 \mathrm{mM}$, contendo $\mathrm{CaCl}_{2} 50 \mathrm{mM}, \mathrm{pH}$ 8,0 na proporção 1:10 (peso:volume).

A ativação do zimogênio da tripsina foi efetuada em tampão Tris- $\mathrm{HCl} 50 \mathrm{mM}$ contendo $\mathrm{CaCl}_{2} 50 \mathrm{mM} \mathrm{e}$ pH 8,0. Em cada dosagem o extrato de pâncreas da amostra-teste foi incubado a $37^{\circ} \mathrm{C}$, durante 30 minutos, com igual volume de extrato duodenal (enteroquinase). Após a ativação do tripsinogênio, a atividade da tripsina foi determinada descontinuamente a $37^{\circ} \mathrm{C}$, de acordo com o procedimento descrito por Kakade et al. (1974). A reação foi iniciada pela adição do substrato Nbenzoil-DL-arginina-p-nitroanilida $($ SIGMA $\AA)$ ao meio de incubação.
A atividade da a-amilase pancreática foi determinada a $37^{\circ} \mathrm{C}$ (Bernfeld, 1955) através da dosagem da maltose liberada, a partir da hidrólise do amido (substrato).

A dosagem de proteína foi efetuada de acordo com o método descrito por Hartree (1972).

Os dados foram submetidos à análise de variância, conforme Pimentel Gomes (1985), segundo os delineamentos descritos anteriormente.

\section{Resultados e Discussão}

Como pode ser observado nas Tabelas 2, 3 e 4, não foram apresentadas interações significativas e, portanto, foram avaliados somente os efeitos principais dos fatores.

O desempenho dos frangos de corte (peso médio, consumo de ração, conversão alimentar e índice de eficiência produtiva) é mostrado na Tabela 2. A dieta com $3.200 \mathrm{kcal}$ de EM proporcionou melhores resultados para todos os parâmetros de desempenho estudados. 
Tabela 2 - Desempenho de frangos de corte submetidos a dietas com 2 níveis de energia (kcal EM/kg) e 3 níveis de probiótico (ppm) no período experimental total (1 a 42 dias de idade).

Table 2 - Performance of broiler chickens fed with 2 energy levels $(\mathrm{kcal} \mathrm{ME} / \mathrm{kg})$ and 3 probiotic levels $(\mathrm{ppm})$ in the total experimental period (1 to 42 days of age)

\begin{tabular}{|c|c|c|c|c|}
\hline $\begin{array}{l}\text { Estatística } \\
\text { Estatistic }\end{array}$ & $\begin{array}{l}\text { Peso médio }(\mathrm{g}) \\
\text { Mean weight }\end{array}$ & $\begin{array}{c}\text { Consumo de ração }(\mathrm{g}) \\
\text { Feed intake }\end{array}$ & $\begin{array}{l}\text { Conversão alimentar } \\
\text { Feed:gain ratio }\end{array}$ & IEP \\
\hline $\begin{array}{l}\mathrm{F} \mathrm{p/Blocos} \\
F \text { Blocks }\end{array}$ & $* *$ & $* *$ & $\mathrm{~ns}$ & $* *$ \\
\hline $\begin{array}{l}\mathrm{F} \text { p/ Energia }(\mathrm{E}) \\
F \text { Energy }(E)\end{array}$ & $* *$ & $* *$ & $* *$ & $* *$ \\
\hline $\begin{array}{l}\mathrm{F} \text { p/Probiótico }(\mathrm{P}) \\
F \text { Probiotic }(P)\end{array}$ & $\mathrm{ns}$ & $\mathrm{ns}$ & $\mathrm{ns}$ & $\mathrm{ns}$ \\
\hline $\begin{array}{l}\mathrm{F} \text { p/ Efeito linear } \\
\text { F Linear effect }\end{array}$ & $\mathrm{ns}$ & $\mathrm{ns}$ & $\mathrm{ns}$ & $\mathrm{ns}$ \\
\hline $\begin{array}{l}\mathrm{F} \mathrm{p} / \mathrm{ExP} \\
F \operatorname{ExP}\end{array}$ & $\mathrm{ns}$ & $\mathrm{ns}$ & $\mathrm{ns}$ & $\mathrm{ns}$ \\
\hline $\begin{array}{l}\mathrm{CV}(\%) \\
\text { Médias energia }\end{array}$ & 3,07 & 3,60 & 3,70 & 5,90 \\
\hline Energy means & & & & \\
\hline $\begin{array}{l}2.900 \\
3.200\end{array}$ & $\begin{array}{l}2.088,67 \mathrm{~b} \\
2.206,11 \mathrm{a}\end{array}$ & $\begin{array}{l}4.143,11 \mathrm{a} \\
3.840,78 \mathrm{~b}\end{array}$ & $\begin{array}{l}2,03 a \\
1,78 b\end{array}$ & $\begin{array}{l}191,88 \mathrm{~b} \\
229,88 \mathrm{a}\end{array}$ \\
\hline $\begin{array}{l}\text { Médias probiótico } \\
\text { Probiotic means }\end{array}$ & & & & \\
\hline $\begin{array}{l}0 \\
200 \\
400\end{array}$ & $\begin{array}{l}2.093,50 \\
2.186,50 \\
2.162,17\end{array}$ & $\begin{array}{l}3.886,50 \\
4.044,17 \\
4.045,17\end{array}$ & $\begin{array}{l}1,90 \\
1,90 \\
1,92\end{array}$ & $\begin{array}{l}209,97 \\
206,91 \\
215,77\end{array}$ \\
\hline
\end{tabular}

ns - não-significativo $(P>0,05) ;{ }^{* *}$ significativo pelo teste $F(P<0,01)$; IEP= índice de eficiência produtiva. Médias, seguidas da mesma letra nas colunas, não diferem estatisticamente entre si $(P>0,01)$ pelo teste $F$. Means followed by same letters are not different $(P>01)$ by $F$ test.

$n s$ - not significant $(P>.05)$; Significant $(P<.01)$ by $F$ test; IEP = index productive efficient.

Com a inclusão do probiótico verificou-se que não houve efeito significativo sobre o desempenho das aves, fato também concluído por Vargas Jr. et al. (2000). Esses autores observaram que, tratamentos com probióticos (Calsporin 10, Finelact), prebiótico (Lactifit, independentemente da característica avaliada (ganho de peso, consumo de ração ou conversão), ou a combinação alimentar), não foram verificadas diferenças estatísticas entre os de ambos os produtos, para frangos de corte até 21 dias de idade.

Em trabalho realizado por Couch (1978), com aves alimentadas com dietas suplementadas com probiótico, verificou-se um aumento de 47 gramas no peso médio, diminuição de $0,4 \%$ na mortalidade e melhoria de 0,81 pontos na conversão alimentar.

Gippert \& Bodrogi (1992), em estudo realizado com patos alimentados com dietas suplementadas com probiótico, verificaram que o suplemento não teve efeito na mortalidade, mas o peso corporal e consumo de ração aumentaram, com melhor conversão alimentar. Por outro lado, em estudo comparativo de um antibiótico e probiótico, Khan et al. (1992) observaram que o ganho de peso e o consumo de ração foram menores, e a conversão alimentar aumentou nos grupos que receberam suplemento probiótico.

A ação dos probióticos parece estar relacionada principalmente a dois fatores: ao número correto de microorganismos vivos utilizados e à presença de estresse nas aves devido às condições de criação. Nesse sentido, Jin et al. (1998), em estudo com frangos de corte, para investigar o efeito de uma mistura de Lactobacillus sobre o desempenho das aves criadas em temperatura quente (média de $30,1^{\circ} \mathrm{C}$ ) e umidade relativa em torno de $95 \%$ (condições consideradas estressantes para as aves), demonstraram maior eficiência em relação às aves de controle tanto no ganho de peso quanto na conversão alimentar, quando foram adicionados Lactobacillus. A ausência de efeito do probiótico pode estar relacionada com as condições sanitárias, pois, não tendo bactérias patogênicas para um desafio, o probiótico também não tem como realizar exclusão competitiva.

A atividade das enzimas do pâncreas dos frangos (expressa em gramas de pâncreas e por kg de peso 
Tabela 3 - Atividade enzimática do pâncreas de frangos de corte submetidos a dois níveis de energia na dieta e três níveis de probiótico, aos 14, 28 e 42 dias de idade

Table 3 - Enzymatic activity of pancreas broiler chickens fed with two energy levels and three probiotic levels in diet, 14, 28 and 42 days of age

\begin{tabular}{|c|c|c|c|c|c|c|}
\hline \multirow[t]{2}{*}{$\begin{array}{l}\text { Estatística } \\
\text { Estatistic }\end{array}$} & \multicolumn{2}{|c|}{$\begin{array}{l}\text { Lipase } \\
\text { Lipase }\end{array}$} & \multicolumn{2}{|c|}{$\begin{array}{l}\text { Amilase } \\
\text { Amylase }\end{array}$} & \multicolumn{2}{|c|}{$\begin{array}{l}\text { Tripsina } \\
\text { Trypsin }\end{array}$} \\
\hline & $\begin{array}{l}\text { U/g pâncreas } \\
\text { U/g pancreas }\end{array}$ & $\begin{array}{c}\mathrm{U} / \mathrm{kg} \text { de PV } \\
\quad U / k g L W\end{array}$ & $\begin{array}{l}\text { U/g pâncreas } \\
\text { U/g pancreas }\end{array}$ & $\begin{array}{c}\mathrm{U} / \mathrm{kg} \text { de } \mathrm{PV} \\
U / k g L W\end{array}$ & $\begin{array}{l}\text { U/g pâncreas } \\
\text { U/g pancreas }\end{array}$ & $\begin{array}{c}\mathrm{U} / \mathrm{kg} \text { de } \mathrm{PV} \\
\mathrm{U} / \mathrm{kg} L W\end{array}$ \\
\hline $\begin{array}{l}\mathrm{F} \text { p/ Blocos } \\
\text { F Blocks }\end{array}$ & $\mathrm{ns}$ & $\mathrm{ns}$ & $\mathrm{ns}$ & $\mathrm{ns}$ & $\mathrm{ns}$ & $\mathrm{ns}$ \\
\hline $\begin{array}{l}\mathrm{F} \text { p/ Energia }(\mathrm{E}) \\
F \text { Energy }(E)\end{array}$ & $\mathrm{ns}$ & $*$ & $\mathrm{~ns}$ & $* *$ & $\mathrm{~ns}$ & $\mathrm{~ns}$ \\
\hline $\begin{array}{l}\mathrm{F} \mathrm{p} / \text { Probiótico }(\mathrm{P}) \\
F \text { Probiotic }(P)\end{array}$ & $\mathrm{ns}$ & $\mathrm{ns}$ & $\mathrm{ns}$ & $\mathrm{ns}$ & $\mathrm{ns}$ & $\mathrm{ns}$ \\
\hline $\begin{array}{l}\mathrm{Fp} / \text { Efeito linear } \\
\text { F Linear effect }\end{array}$ & $\mathrm{ns}$ & $\mathrm{ns}$ & $\mathrm{ns}$ & $\mathrm{ns}$ & $\mathrm{ns}$ & $\mathrm{ns}$ \\
\hline $\begin{array}{l}\mathrm{F} \mathrm{p} / \text { Idade }(\mathrm{I}) \\
F \text { Age }(A)\end{array}$ & $* *$ & $* *$ & $* *$ & $* *$ & $* *$ & $* *$ \\
\hline $\begin{array}{l}\mathrm{Fp} / \text { Efeito linear } \\
\text { F Linear effect }\end{array}$ & $* *$ & $* *$ & $* *$ & $* *$ & $* *$ & $* *$ \\
\hline $\begin{array}{l}\text { F ExP } \\
F \operatorname{ExP}\end{array}$ & $\mathrm{ns}$ & $\mathrm{ns}$ & $\mathrm{ns}$ & $\mathrm{ns}$ & $\mathrm{ns}$ & $\mathrm{ns}$ \\
\hline $\begin{array}{l}\text { FExI } \\
\text { FExA }\end{array}$ & $\mathrm{ns}$ & $\mathrm{ns}$ & $\mathrm{ns}$ & $\mathrm{ns}$ & $\mathrm{ns}$ & $\mathrm{ns}$ \\
\hline $\begin{array}{l}\text { FPxI } \\
\text { FPxA }\end{array}$ & $\mathrm{ns}$ & $\mathrm{ns}$ & $\mathrm{ns}$ & $\mathrm{ns}$ & $\mathrm{ns}$ & $\mathrm{ns}$ \\
\hline $\begin{array}{l}\text { FExPxI } \\
F \operatorname{ExPxA}\end{array}$ & $\mathrm{ns}$ & $\mathrm{ns}$ & $\mathrm{ns}$ & $\mathrm{ns}$ & $\mathrm{ns}$ & $\mathrm{ns}$ \\
\hline $\begin{array}{l}\mathrm{CV}(\%) \\
\text { Médias energia }\end{array}$ & 13,73 & 15,16 & 18,64 & 22,36 & 27,91 & 31,09 \\
\hline $\begin{array}{l}\text { Energy means } \\
2.900 \\
3.200\end{array}$ & $\begin{array}{l}2.336,45 a \\
2.356 .16 a\end{array}$ & $\begin{array}{l}7.070,79 a \\
6.442 .06 b\end{array}$ & $\begin{array}{l}27,96 a \\
26,81 a\end{array}$ & $\begin{array}{l}79,48 \mathrm{a} \\
67,37 \mathrm{~b}\end{array}$ & $\begin{array}{l}6.003,03 a \\
5.779 .13 a\end{array}$ & $\begin{array}{l}17.103,1 \mathrm{a} \\
14.523,3 \mathrm{a}\end{array}$ \\
\hline $\begin{array}{l}\text { Médias probiótico } \\
\text { Probiotic means }\end{array}$ & & & & & & \\
\hline $\begin{array}{l}0 \\
200 \\
400\end{array}$ & $\begin{array}{l}2.332,87 \\
2.236,50 \\
2.469,55\end{array}$ & $\begin{array}{l}6.828,67 \\
6.558,61 \\
6.882,00\end{array}$ & $\begin{array}{l}27,04 \\
26,13 \\
28,99\end{array}$ & $\begin{array}{l}74,59 \\
69,17 \\
76,48\end{array}$ & $\begin{array}{l}5.878,54 \\
5.781,97 \\
6.012,73\end{array}$ & $\begin{array}{l}16.090,90 \\
15.413,41 \\
15.935,28\end{array}$ \\
\hline $\begin{array}{l}\text { Médias idades } \\
\text { Ages means }\end{array}$ & & & & & & \\
\hline $\begin{array}{l}14 \\
28 \\
42\end{array}$ & $\begin{array}{l}2.659,67 \\
2.365,71 \\
2.013,54\end{array}$ & $\begin{array}{c}10.047,50 \\
6.617,33 \\
3.604,37\end{array}$ & $\begin{array}{l}21,82 \\
28,05 \\
32,29\end{array}$ & $\begin{array}{l}83,16 \\
78,91 \\
58,17\end{array}$ & $\begin{array}{l}4.331,89 \\
6.721,57 \\
6.619,78\end{array}$ & $\begin{array}{l}16.499,70 \\
18.996,41 \\
11.943,40\end{array}$ \\
\hline
\end{tabular}

ns - não-significativo $(P>0,05)$; $e^{* *}$ significativo pelo teste $F(P<0,05)$ e $(P<0,01)$, respectivamente; $P V=$ peso vivo ; $U=$ unidades. Médias, seguidas da mesma letra nas colunas, não diferem estatisticamente entre si $(P>0,01)$ pelo teste $F$.

$n s-$ not significant $(P>0.05)$; Significant $(P<0.05)$ and $(P<0.01)$ by $F$ test; $L W=$ Live weight; $U=$ units.

Means followed by same letters are not different $(P>0.01)$ by $F$ test.

vivo) submetidos a dietas contendo dois níveis energéticos (2900 e 3200 kcal de EM) e adição de 0; 200 e 400 ppm de probiótico é mostrada na Tabela 3. Não foram observados efeitos significativos $(\mathrm{P}>0,05)$ para a inclusão do probiótico na dieta. Por outro lado, a atividade enzimática do pâncreas diminuiu significativamente $(\mathrm{P}<0,01)$ em função da idade das aves, com exceção da amilase e tripsina, quando expressas por gramas de pâncreas.
Com relação à energia das dietas, verificou-se que, quando a atividade enzimática pancreática foi expressa em unidades/kg de peso vivo, ocorreu um efeito significativo sobre as atividades da lipase e amilase $(\mathrm{P}<0,05)$, sendo a maior atividade encontrada para os animais alimentados com dieta contendo 2.900 kcal de EM, com exceção da lipase expressa em unidades/g de pâncreas.

Nir et al. (1993), em experimento com aves de

\section{R. Bras. Zootec., v.32, n.1, p.200-207, 2003}


corte até 15 dias de idade, observaram que, quando a atividade enzimática pancreática da lipase, amilase, tripsina e quimotripsina foi relacionada ao peso vivo, houve diferença significativa, e essa atividade aumentou com a idade. Semelhante ao observado por diferentes autores (Krogdhal \& Sell, 1989; Nir et al., 1993; O'Sullivan et al., 1992), a atividade das enzimas pancreáticas foi maior no $14^{\circ}$ dia e diminuiu significativamente em função da idade das aves (até 42 dias de idade), quando expressa por quilo de peso vivo. Esse fato pode estar relacionado ao desenvolvimento alométrico do pâncreas, que parece atingir seu pico máximo ao redor do $14^{\circ}$ dia de idade, tendendo, então, a diminuir, não havendo portanto, uma correlação entre o aumento do órgão e o respectivo aumento da atividade das enzimas.

Segundo Noy \& Sklan (1995), apesar da secreção da amilase ser relativamente baixa para frangos jovens no $4^{\circ}$ dia de idade e, a partir daí, aumentar com a idade, a digestão do amido sempre foi acima de $85 \%$ entre 4 e 21 dias de idade.

Apesar de vários autores (Sabb et al., 1986; Ballestra et al., 1990; Belleville et al., 1978) enfatizarem que o teor energético de dietas exerce grande influência na atividade de lipase pancreática, no presente estudo, esse efeito não foi significativo, pois, em termos de ingestão calórica (kcal de EM/dia/ ave), os dois tratamentos continham quantidades semelhantes (286 vs $293 \mathrm{kcal}$ de EM/dia/ave). Segundo Nir et al. (1993), o efeito do nutriente sobre a atividade enzimática pode ser mais pronunciado no período inicial (primeiras semanas) do desenvolvi- mento do intestino delgado e do pâncreas.

$\mathrm{Na}$ Tabela 4, estão apresentadas as atividades das enzimas da mucosa intestinal de frangos de corte em função dos tratamentos.

Os resultados obtidos mostraram que a atividade da tripsina intestinal, expressa por gramas de tecido, aumentou com a idade das aves. Quando as atividades foram expressas por $\mathrm{kg}$ de peso vivo, houve uma diminuição significativa $(\mathrm{P}<0,01)$ para todas as enzimas em função da idade.

Embora a atividade da amilase da mucosa intestinal tenha sido significativamente $(\mathrm{P}<0,01)$ afetada pelo teor energético da dieta, com maior atividade encontrada na mucosa de frangos alimentados com dieta contendo $2.900 \mathrm{kcal}$ de EM, as atividades da lipase e tripsina na mucosa intestinal não foram influenciadas pelo nível de energia.

A adição de probiótico também não teve efeito significativo $(\mathrm{P}>0,05)$ sobre a atividade de nenhuma das enzimas intestinais.

A baixa atividade das enzimas também foi verificada por Pinchasov et al. (1990) que mostraram que a atividade das enzimas digestivas no intestino delgado são correspondentes com a quantidade de conteúdo intestinal e variam diariamente de acordo com o estado de alimentação. Esses autores verificaram ainda que a redução na atividade enzimática no conteúdo intestinal de aves com alimentação intermitente não foi acompanhada por um acúmulo de enzimas no pâncreas, sugerindo que a síntese de enzimas pancreáticas é também regulada pela presença do quimo no intestino. 
Tabela 4 - Atividade enzimática intestinal de frangos de corte submetidos a dois níveis de energia na dieta e três níveis de probiótico, aos 14, 28 e 42 dias de idade

Table 4 - Enzymatic activity intestinal of broiler chickens fed two energy levels and three probiotic levels in diet, 14, 28 and 42 days of age

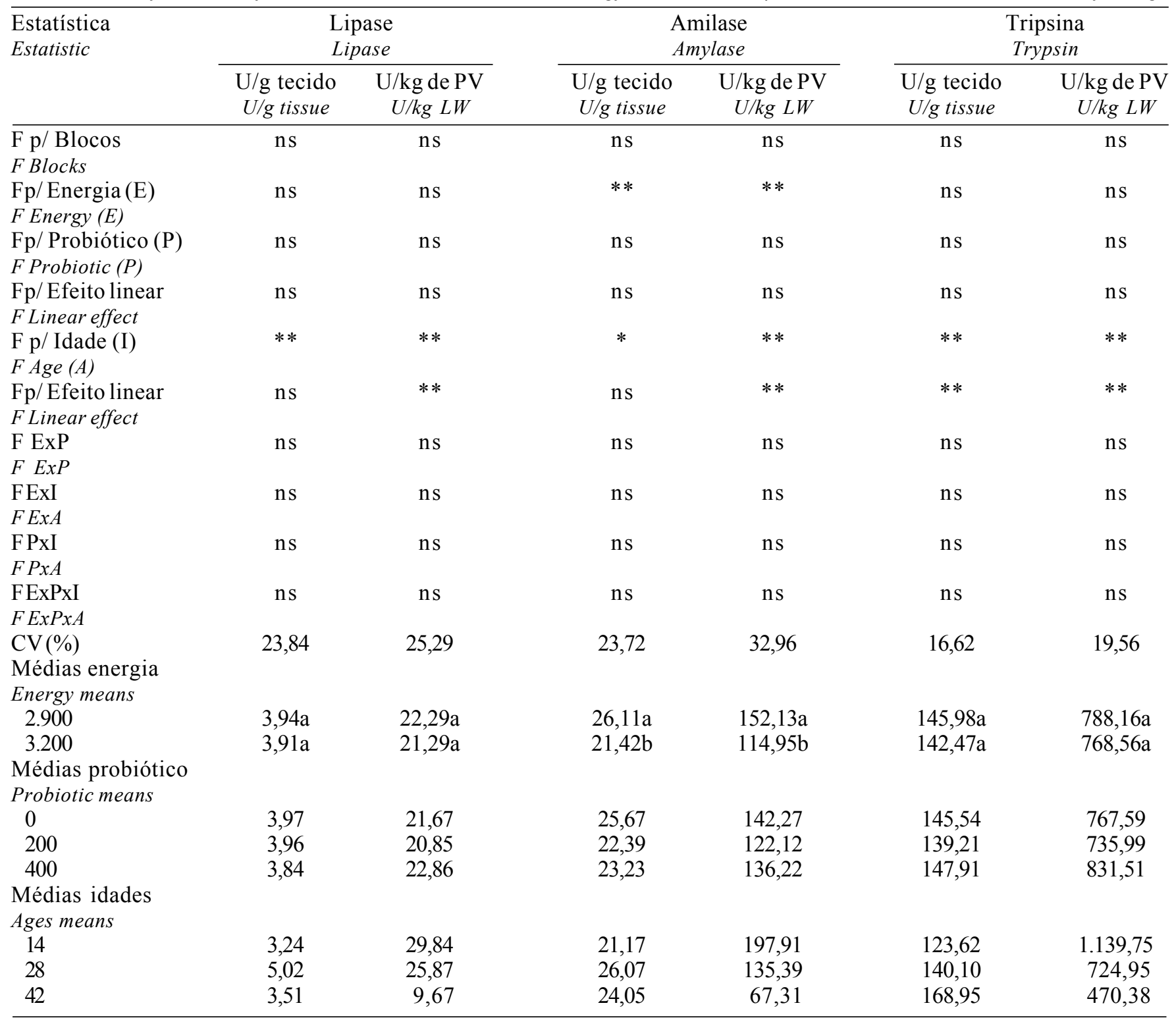

ns - não-significativo $(P>0,05) ;{ }^{*} e^{* *}$ significativo pelo teste $F(P<0,05)$ e $(P<0,01)$, respectivamente; $P V=$ peso vivo; $U=$ unidades. Médias, seguidas da mesma letra nas colunas, não diferem estatisticamente entre si $(P>0,01)$ pelo teste $F$.

$n s$ - not significant $(P>0.05)$; Significant $(P<0.05)$ and $(P<0.01)$ by $F$ test; $L W=$ Live weight; $U=$ units.

Means followed by same letters are not different $(P>0.01)$ by $F$ test.

\section{Conclusões}

Os resultados obtidos no presente estudo mostraram que a adição de probiótico (Bacillus subtilis), na dieta de frangos de corte, não compromete o desempenho e nem a atividade das enzimas digestivas analisadas.

\section{Agradecimento}

Ao Conselho Nacional de Desenvolvimento Científico (CNPq), pela bolsa de pesquisa concedida ao autor principal para execução do projeto. À FATEC, pela doação do probiótico. À FAPESP, pelo auxílio financeiro para a realização deste projeto. 


\section{Literatura Citada}

BALLESTRA, M.C.; MANAS, M.; MATAIX, F.J. et al. Longterm adaptation of pancreatic response by dogs to dietary fats of different degrees of saturation: olive and sunflower oil. British Journal of Nutrition, v.64, p.487, 1990.

BELLEVILLE, J.; PROST, J.; GILLET, M. Effects des régimes riches en triglycérides et en phospholipides sur les activites de la lipase et de la phospholipase A du suc pancréatique et du pancréas de rat. Archives Internacionales de Physiologie et de Biochimie, v.86, p.631, 1978.

BERNFELD, P. Amylases a and b. In: COLOWICK, S.B.; KAPPLAN, N.O. (Eds.) Methods in Enzymology. New York: Academic Press, 1955. v.1, p.149-153.

BROCKMAN, H.L. Triglyceride lipase from porcine pancreas. In: BOYER, P.D. (Ed.) Methods in enzymology. New York: Academic Press, 1981. v. 71, p.619-627.

COUCH, J.R. Poultry researchers outline benefits of bacteria, fungistatic compounds, other feed addtivies. Feedstuffs, v.50, n.14, p.6, 1978.

GIPPERT, T.; BODROGI, G. Lacto-Sacc i the feeding of broiler duck. In: INTERNATIONAL SYMPOSIUM ON WATERFOWL, 9., 1992. Proceedings... Pisa, 1992. p.150-151.

HARTREE, E.F. Determination of protein: a modification of the Lowry method that gives a linear photometric response. Analytical Biochemistry, v.48, p.422-427, 1972.

JIN, L.Z.; HO, Y.W.; ABDULLAH, N. et al. Effects of adherent Lactobacillus cultures on growth, weight of organs and intestinal microflora and volatile fatty acids in broilers. Animal and Feed Science Technology, v.70, p.197-209, 1998.

KAKADE, M.L.; RACKIS, J.J.; McGHEE, J.G. Determination of trypsin inhibitor activity of soy products: A collaborative analysis of an improved procedure. Cereal Chemistry, v.51, p.376-382, 1974.

KHAN, M.L.; ULLAH, I.; JAVED, M.T. Comparative study of probiotics, T. M. 50 Biovin-40 and Albac on the performance of broiler chicks. Pakistan Veterinary Journal, v.12, p.145-147, 1992.

KOZASA, M. Probiotics for animal use in Japan. Revue Scientifique et Technique de $L$ Office International des Epizooties, v.8, n.2, p.517-531, 1989.

KROGDAHL, A.; SELL, J.L. Influence of age on lipase, amylase, and protease activities in pancreatic tissue and intestinal contents of young turkeys. Poultry Science, v.68, n.11, p.1561-1568, 1989.
LIMA, A.C.F. Efeito do uso de probiótico sobre o desempenho e atividade de enzimas digestivas de frangos de corte. Jaboticabal: Universidade Estadual Paulista, 1996. 70p. Dissertação (Mestrado em Zootecnia) - Universidade Estadual Paulista, 1996.

NIR, I.; NITSAN, Z. Metabolic and anatomical adaptations of light-bodied chicks to intermitent feeding. British Poultry Science, v.20, p.61-71, 1979.

NIR, I.; NITSAN, Z.; MAHAGNA, M. Comparative growth and development of the digestive organs and of some enzymes in broiler and egg type chicks after hatching. British Poultry Science, v.34, p.523-532, 1993.

NOY, Y.; SKLAN, D. Digestion and absorption in the young chick. Poultry Science, v.74, n.2, p.366-373, 1995.

NATIONAL RESEARCH COUNCIL - NRC. Nutrient requirements of poultry. Washington, D.C.: National Academy Press, 1994. 155p.

O'SULLIVAN, N.P.; DUNNINGTON, E.A.; LARSEN, A.S. et al. Correlated responses in lines of chickens divergently selected for fifty-six-day body weight. 3. Digestive enzymes. Poultry Science, v.71, n.4, p.610-617, 1992.

PIMENTEL GOMES, F. Curso de estatística experimental 11.ed. Piracicaba: Nobel, 1985. 466p.

PINCHASOV, Y.; NIR, I.; NITSAN, Z. Metabolic and anatomical adaptations of heavy-bodied chicks to intermitent feeding. 2. Pancreatic digestive enzymes. British Poultry Science, v.31, p.769-777, 1990.

SABB, J.E.; GODFREY, P.M.; BRANNON, P.M. Adaptative response of rat pancreatic lipase to dietary fat: effects of amount and type of fat. Journal of Nutrition, v.116, p.892899,1986

SARDA, L.; DESNUELLE, P. Action de la lipase pancréatique sur les esters en émulsion. Biochimica et Biophysica Acta, v.30, p.513-521, 1958.

VARGAS Jr., J.G.; TOLEDO, R.S.; ALBINO, L.F.T. et al. Uso de probióticos e prebióticos em rações de frangos de corte. In: CONFERÊNCIA APINCO DE CIÊNCIA E TECNOLOGIA AVÍCOLAS, 2000, Campinas. Anais... Campinas: Apinco, 2000. p.31.

Recebido em: 04/05/01 Aceito em: 26/08/02 